\title{
The 1998 Earthquake Sequence South of Long Valley Caldera, California: Hints of Magmatic Involvement
}

\author{
by S. E. Hough, R. S. Dollar, and P. Johnson
}

\begin{abstract}
A significant episode of seismic and geodetic unrest took place at Long Valley Caldera, California, beginning in the summer of 1997. Activity through late May of 1998 was concentrated in and around the south moat and the south margin of the resurgent dome. The Sierran Nevada block (SNB) region to the south/southeast remained relatively quiet until a $M 5.1$ event occurred there on 9 June 1998 (UT). A second $M 5.1$ event followed on 15 July (UT); both events were followed by appreciable aftershock sequences. An additional, distinct burst of activity began on 1 August 1998. The number of events in the August sequence (over the first week or two) was similar to the aftershock sequence of the 15 July 1998 M 5.1 event, but the later sequence was not associated with any events larger than $M$ 4.3. All of the summer 1998 SNB activity was considered tectonic rather than magmatic; in general the SNB is considered an unlikely location for future eruptions. However, the August sequence-an "aftershock sequence without a mainshock" - is suggestive of a strain event larger than the cumulative seismotectonic strain release. Moreover, a careful examination of waveforms from the August sequence reveals a small handful of events whose spectral signature is strikingly harmonic. We investigate the waveforms of these events using spectral, autocorrelation, and empirical Green's function techniques and conclude that they were most likely associated with a fluid-controlled source. Our observations suggest that there may have been some degree of magma or magma-derived fluid involvement in the 1998 SNB sequence.
\end{abstract}

\section{Introduction}

The Long Valley Caldera is a complex volcanic system along the eastern Sierra Nevada, California (Fig. 1). A detailed overview of the geology and unrest since 1980 can be found elsewhere (Hill et al., 1985; Bailey, 1989; Hill et al., 1990). A brief overview will provide a context for the interpretation of our seismological observations.

A large $\left(600 \mathrm{~km}^{3}\right)$ caldera-forming eruption occurred 760,000 years ago; smaller-scale activity $\left(0.001-1.0 \mathrm{~km}^{3}\right.$ per eruption) has taken place over the last few thousand years along the Mono/Inyo chain of craters, west and northwest of the caldera (Sieh and Bursik, 1986; Bailey, 1989). The area has been monitored intensely since 1980, when the region was shaken by four $M 6$ earthquakes and many thousands of smaller events. Although geodetic data reveal that deformation since 1980 has been associated primarily with uplift of the resurgent dome (e.g., Savage and Clark, 1982; Langbein et al., 1995), most of the seismic-moment release associated with the 1980 sequence occurred not within the caldera, but within the Sierran Nevada block (SNB) immediately to the south-southeast (see Fig. 1).

A significant seismic swarm in early 1983 was associated with two $M 5+$ events in the south moat and led to the establishment of a high-precision deformation network that has been in operation since that time (Hill, 1984). Another burst of seismic activity and deformation occurred in 1989 (Hill et al., 1990). Geodetic data from this episode was interpreted as resulting from continuing inflation beneath the resurgent dome as well as a dike intrusion event underneath Mammoth Mountain, on the southwest margin of the caldera (Langbein et al., 1995). Deformation over the next four years was dominated by inflation of the resurgent dome, with a possible component of dike injection beneath the Mono/ Inyo craters (Marshall et al., 1997).

Given the scattered distribution of seismic activity and complex deformation observed since 1980, it has not been clear what part of the caldera region should be considered the most likely site of future volcanic activity. Although the geologic record over the past 40,000 years suggests the Mono/Inyo chain to be the most likely site, relatively little recent seismicity has occurred along this chain. Some recent seismicity has occurred beneath Mammoth Mountain itself, most notably a swarm of approximately six months' duration in 1989 (Hill et al., 1990). However, the most recent eruptions of this cumulovolcano were on the order of 50,000 


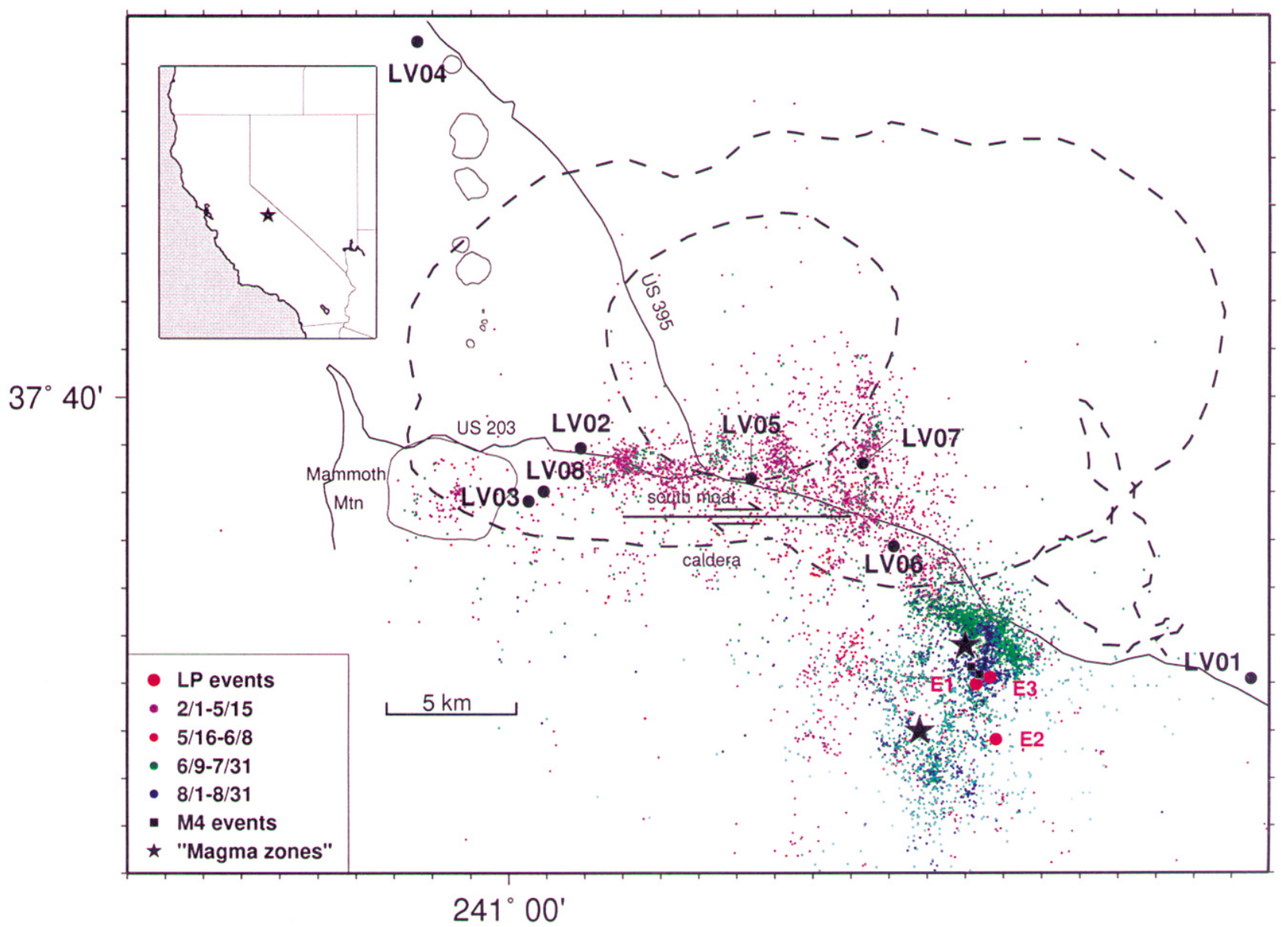

Figure 1. Map of the Long Valley region, including perimeter of caldera, resurgent dome and Crowley Lake (dashed lines), highways (solid lines), Mammoth Mountain and the Mono/Inyo craters (solid lines), and STORMS stations LV01-LV08 (circles). Different-colored small dots correspond to NCSN-located seismicity between 1 February and 15 May 1998 (purple), 16 May and 8 June 1998 (red), 9 June and 31 July 1998 (green), and 1 August and 31 August 1998 (blue). Larger red dots indicate locations of events E1, E2, and E3 discussed in the text; small black squares close to events E1 and E3 indicate location of two $M>4$ events that occurred approximately 10 minutes before each of these hybrid-LP events. Black stars indicate possible magma zones inferred by previous studies.

years ago (Bailey, 1989). The south moat region immediately south of the resurgent dome, which experienced rhyolitic eruptions approximately 300,000 years ago (see Bailey and Hill [1990] for a summary), has experienced considerable seismic activity since 1980. Because of the absence of both previous (recent) volcanism and present-day geothermal features, the SNB to the south-southeast of the caldera has generally been considered an unlikely candidate for volcanic activity in spite of its substantial recent earthquake activity. The seismic activity in this region has generally been regarded as tectonic, either an accommodation of strain resulting from inflation of the resurgent dome (Savage and Clark, 1982) or a reflection of the ongoing extensional tectonic processes.
Several lines of evidence have suggested the presence of magma and or magmatic activity within the SNB. The evidence, however, remains ambiguous. A non-double-couple component was inferred for two of the largest events within the 1980 sequence, events that occurred within the SNB (Julian and Sipkin, 1985; Miller et al., 1998). However, the volumetric component of these events was unresolvably small (Miller et al., 1998), leaving open the possibility that the apparent non-double-couple component reflected complex shear faulting (Wallace, 1985). The presence of magma bodies within the SNB has also been inferred by previous studies (e.g., Ryall and Ryall, 1983; Peppin et al., 1989) based on indirect evidence such as velocity anomalies and $S$-wave shadowing. While these results are intriguing, on- 
going monitoring efforts have remained focused on the caldera and the Mono/Inyo chain, where evidence for ongoing magmatic activity has been unambiguous in recent years.

The most recent period of unrest began in summer of 1997; observed ground deformation over the last six months of the year exceeded the 1989-1990 episode (10 cm of uplift of the resurgent dome). Deformation models inferred using different types of geodetic data differ in detail, but all suggest an intrusion in the south moat region-an inflating "Mogi" source—at a depth between 5 and $12 \mathrm{~km}$ (e.g., Langbein et al., 1998; Simons et al., 1998). An inversion of gravity data by Battaglia et al. (1998) rules out the possibility that the deformation is caused by geothermal activity. Unlike the 1989 deformation event, a significant right-lateral deformation event within the south moat region was also inferred (Langbein et al., 1998).

The deformation rate within the caldera slowed to nearly zero by mid-1998 (Langbein et al., 1998); seismic activity in the south moat region largely died down as well. However, substantial seismic unrest did occur elsewhere in the Long Valley region during the summer of 1998. In contrast to the 1997 sequence, which was concentrated in the south moat and Mammoth Mountain regions, the unrest that began in mid-1998 was concentrated in the SNB region. In this article we focus on the more recent sequence of seismic events that occurred within the SNB.

\section{Data and Analysis}

\section{Data}

Between early February and late September of 1998, we operated an array of portable digital seismometers in the Long Valley region to provide supplemental three-component coverage of the ongoing seismic unrest. In the absence of portable instrumentation, seismic recording in the Long Valley region is provided by the Northern California Seismic Network (NCSN), approximately 20 short-period vertical stations (see Hill et al., 1997); and a single broadband station, MLAC, operated by TriNet in the central part of the south moat region. The Short-Term Observation of Regional Mammoth Seismicity (STORMS) deployment we describe here comprised eight sites instrumented with portable, digital RefTek recorders and L-22 2-Hz sensors (see Fig. 1). Data were recorded with a gain of $32 \mathrm{~dB}$ and sampled at 100 samples/sec.

Between 5 February and 27 September 1998, the STORMS deployment recorded over 3500 earthquakes that correlate with events in the NCSN catalog, including over 2000 that occurred in the SNB. The detection threshold of the STORMS network was no better than that of the NCSN in the caldera region, so network locations and magnitudes are available for all associated STORMS events. In this study, we will use the network locations and (local) magnitudes. In Figure 1 we present the NCSN-determined locations of events between early February and late August. A clear shift in seismicity distribution occurred in mid-May. As illustrated in Figure 2(a), a small upswing in SNB activity on approximately 20 May presaged the larger increase that occurred with the 9 June $M 5.1$ event. The second large increase evident in Figure 2(b) corresponds to the second $M$ 5.1 event on 15 July.

A curious feature of Figure 2(b) is the third sizable burst of seismicity in the SNB, which began on 1 August. Although roughly comparable in cumulative number (and possibly longer in duration) to the first two, this sequence of events is not associated with a single large mainshock. The sequence includes three $M>4$ events: $M 4.3$ at 06:01 GMT on 1 August; $M 4.3$ at 14:45 on 2 August; and $M 4.1$ at 13:44 on 5 August (see Fig. 1).

\section{Harmonic Events?}

A routine perusal of STORMS waveform data uncovered three events whose time domain and/or spectral signatures are striking, and all occurred in early August 1998: a $M 1.3$ event that occurred at 06:11 GMT on 1 August, a $M 2.2$ event at 09:53 on 1 August, and a $M 2.7$ event 14:51 on 2 August. These events, henceforth termed E1, E2, and E3, respectively, occurred at (NCSN-determined) depths of 3.7, 1.9 , and $7.0 \mathrm{~km}$. Events E1, E2, and E3 were located using data from 12, 7, and 29 stations, respectively. The rms misfit for all three events was $0.03-0.06 \mathrm{sec}$, a typical misfit for well-located NCSN events. Johnson and Seeber (1999) have performed a master-event relocation of Long Valley events, including the summer 1998 sequence. Applying a stringent constant station set requirement, they obtain high-quality relocations for only a small subset of the total events (generally
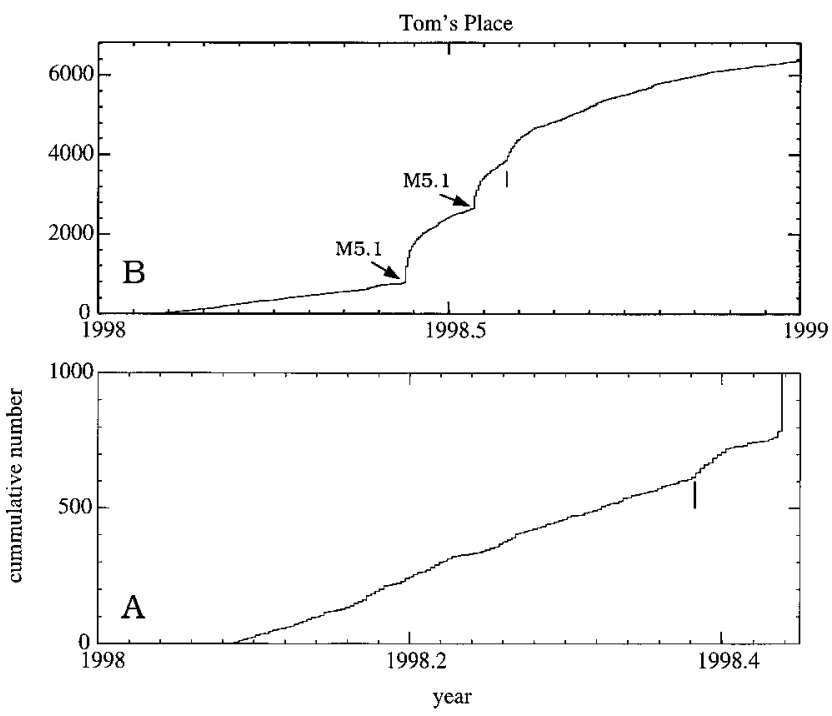

Figure 2. Cumulative seismicity count for events occurring south of Long Valley Caldera (i.e., within the Sierran mountain block) (a) between 1 February and 9 June 1998 and (b) between 1 February and 31 December 1998. Small lines indicate day 20 May 1998 (bottom panel) and 1 August 1998 (top panel). 
the larger ones). They obtain a relocation for event E3, and it is not significantly different from the NCSN location (the location shown in Figure 1, at a depth of approximately $7 \mathrm{~km}$ ).

We note that two of these three events occur within 10 minutes after one of the $M 4+$ events mentioned previously. Event E1 occurred 10 minutes after the 06:01 GMT $M 4.3$ on 1 August 1998 and event E3 occurred 6 minutes after the 14:45 GMT $M 4.3$ event on 2 August 1998. The NCSNdetermined depths for the 1 August and 2 August $M 4.3$ events were 6.2 and $6.8 \mathrm{~km}$; the master-event relocations by Johnson and Seeber (1999) yield depths of 3.8 and 7.4 for the two events, respectively.

Figure 3 presents the time series and whole-record spectra for the vertical component of event E1 recorded at five STORMS stations. Spectra are calculated using a standard FFT with a 9 -sec window bracketing the $P$ and $S$ waves; the
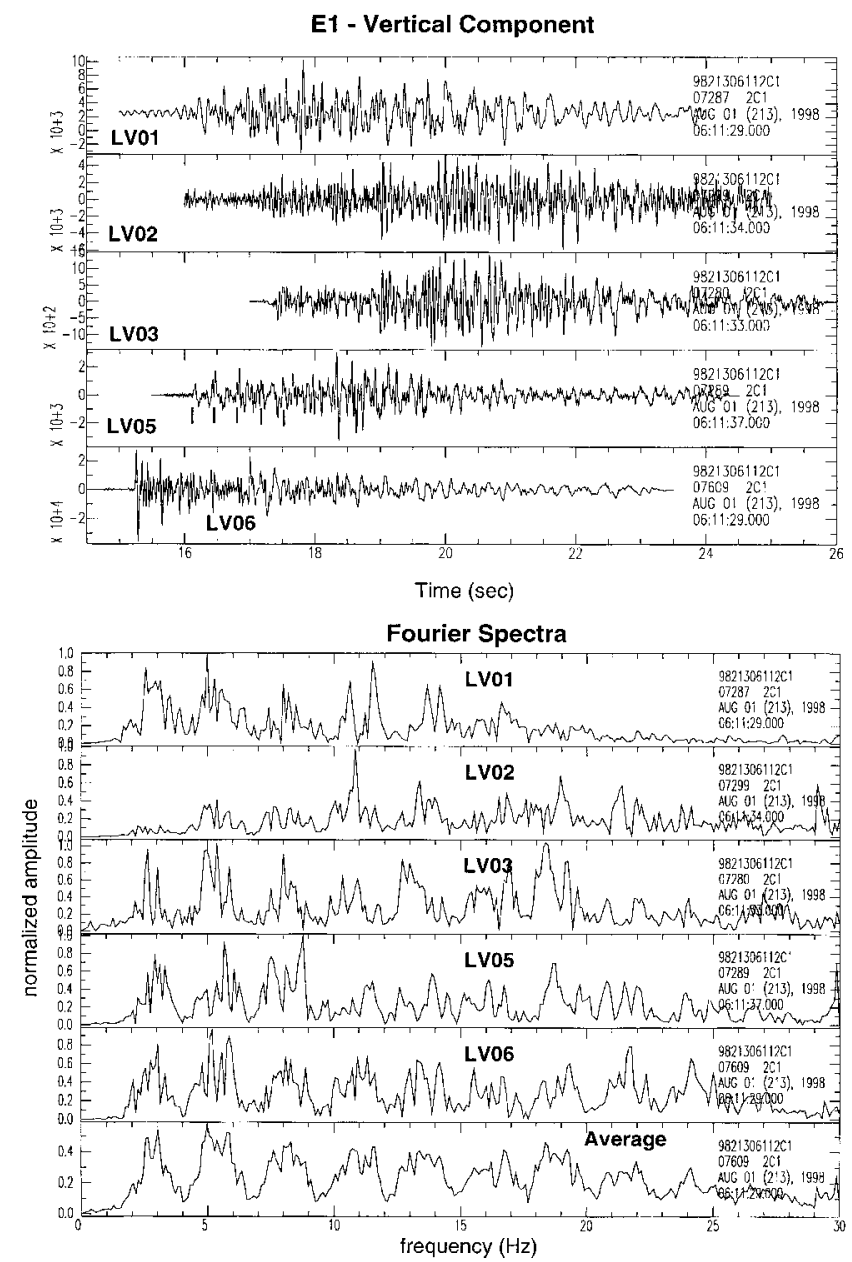

Figure 3. Time series (top) and Fourier spectra (bottom) corresponding to event E1 recorded at stations LV01, LV02, LV03, LV05, and LV06. Spectra are estimated from 9-sec windows bracketing the initial $P$ - and $S$-wave arrivals. An average spectrum is also shown; the average is generated by normalizing the peaks of each individual spectrum to one and then computing the arithmetic average. data are demeaned and tapered prior to the spectral estimation. Although the time series are unremarkable, the spectra corresponding to these recordings are striking. At every station, a suite of similar spectral peaks is clearly evident; the peaks are even more regular in an amplitude normalized average of the five individual spectra.

To further illustrate the harmonic nature of the time series from E1, Figure 4 presents an autocorrelation calculated from the vertical component of the time series recorded at station LV05. For this calculation, we use a $2.5-\mathrm{sec}$ window bracketing the $P$ wave. For comparison, Figure 4 also presents the autocorrelation functions for two other events with similar magnitude and location (Table 1). A pronounced series of peaks is evident in the autocorrelation function corresponding to event E1; although of relatively low amplitude, their character is clearly distinguished from the random nature of the autocorrelations of the other events (away from the 0 -sec lag). In fact, a nearly periodic signal is apparent in the raw data, as highlighted by the tick marks below the trace from station LV05 in Figure 3. Interestingly, although the time series most strongly suggests repeated peaks at 0.35 $0.37 \mathrm{sec}$ intervals, the autocorrelation reveals a periodic

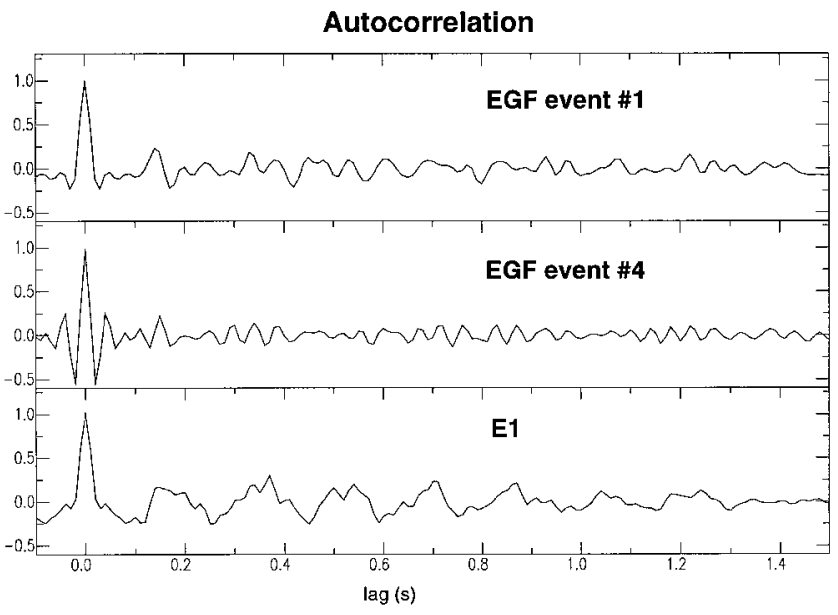

Figure 4. Normalized autocorrelation function corresponding to three events recorded at station LV05: E1 (bottom) and two events from Table 1 (middle and top).

Table 1

Harmonic Events

\begin{tabular}{cccccccccc}
\hline Event & Year & Day & hr:mn & Lat. & Long. & errh & errz & Depth & m \\
\hline E1 & 98 & 213 & $06: 11$ & 37.5690 & 118.7893 & 0.30 & 0.98 & 3.71 & 1.4 \\
E2 & 98 & 213 & $09: 53$ & 37.5472 & 118.7868 & 0.51 & 0.46 & 1.90 & 2.2 \\
E3 & 98 & 214 & $14: 51$ & 37.5665 & 118.7953 & 0.28 & 0.59 & 6.97 & 2.7 \\
\hline
\end{tabular}

Assigned event number; Year, Julian day; GMT time; latitude and longitude in decimal-degrees; horizontal and vertical errors in $\mathrm{km}$; depth in $\mathrm{km}$; magnitude as determined by NCSN. All values (in this and other tables) given to same number of significant figures as reported by NCSN. 
signal at half this interval. Peaks at $0.15-0.18$ sec are apparent in the raw time series, but at a lower amplitude.

Spectra from events E2 and E3 also exhibit a clear harmonic peak, although with somewhat less consistent overtones (Figs. 5 and 6). However, the time series for these events are more suggestive of earthquakes known as "hybrid long-period" (LP) events. That is, a relatively long-period signal follows an initial higher-frequency $P$ and $S$ wave. In all cases, similar peaks are observed on the horizontal components as well as the vertical (e.g., Figure 6(b)). However, the harmonic spectral signature of the vertical components is generally more clear, which is not surprising since the vertical spectra are expected to be less affected by classic site-response amplifications and resonances associated with near-surface low-velocity layers.

Event E3 is large enough ( $M$ 2.7) to be investigated further using empirical Green's function (EGF) analysis (Mueller, 1985). We identify a set of five events with $M$ between 1.3 and 1.5 with hypocentral locations similar to that of E3 for use as EGF events (Table 2) to obtain a deconvolved source spectrum for event E3 (the "mainshock"). Using all E3 and EGF (vertical-component) recordings from stations LV01, LV03, LV05, and LV06, we use demeaned, tapered 9-sec windows bracketing the main arrivals to compute Fourier spectra and then perform frequency-domain deconvolutions. The EGF and mainshock spectra are smoothed over $4 \mathrm{~Hz}$ bandwidth prior to the deconvolutions. In principle, the EGF method corrects the mainshock for all path and site effects and the resulting (relative) deconvolved source spectrum should be station independent. We therefore calculate an amplitude-normalized average of the source spectra (calculated with different EGF events) at each station, then combine these results to obtain a final amplitude-normalized source spectrum averaged over all four stations. The resulting spectrum (Fig. 7) is similar to the average of the raw spectra but smoother, with a peak at $\approx 2 \mathrm{~Hz}$ and at least one suggested overtone at $8-9 \mathrm{~Hz}$.

We repeat the above EGF analysis using the 06:01 1 August 1998 M 4.3 event as a mainshock. Only three stations are used for this analysis because the mainshock recording at station LV06 was clipped. In all other respects the analysis was identical to that described already. The results, shown in Figure 7, reveal a source spectrum for the $M 4.3$ event that is consistent with that expected for a tectonic earthquake. We use the standard formulation (Keilis-Borok, 1959) to compute stress drop estimates,

$$
\sigma=M_{\mathrm{o}}\left(\frac{f_{\mathrm{c}}}{0.49 \beta_{\mathrm{s}}}\right)^{3}
$$

where $\beta_{\mathrm{s}}$ is the shear-wave velocity at the source (assumed here to be $3.2 \mathrm{~km} / \mathrm{sec}$ ), and $\sigma$ is an estimate of dynamicstress drop that can be equated (given a specified source model) to static stress-drop (e.g., Brune, 1970). A corner frequency of 1-2 Hz implies a Brune stress drop of 0.7-5.6
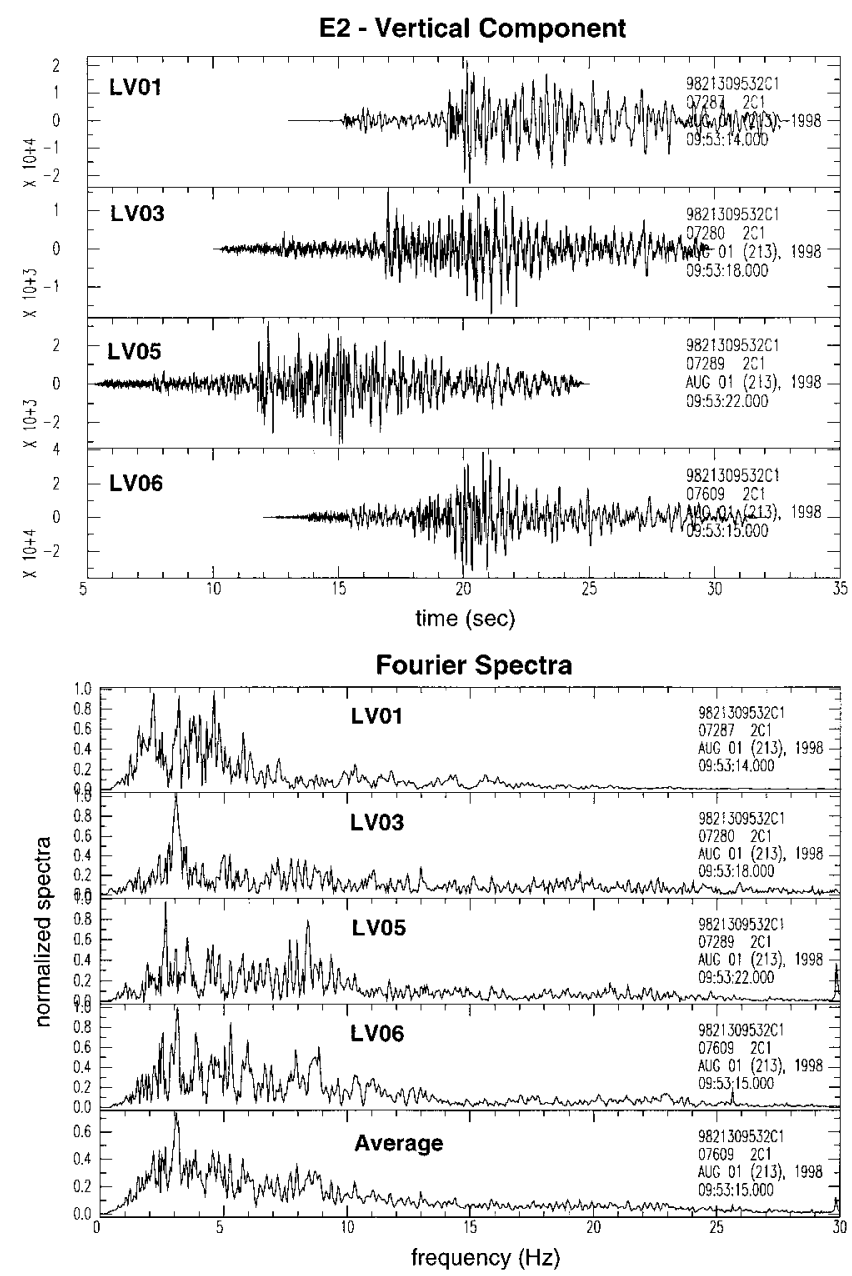

Figure 5. Time series (top) and Fourier spectra (bottom) corresponding to event E2 recorded at stations LV01, LV03, LV05, and LV06. Spectra are estimated from 9-sec windows bracketing the initial $P$ - and $S$-wave arrivals. An amplitude-normalized average spectrum is also shown.

MPa. This result is entirely consistent with the range of values obtained for moderate earthquakes in nonvolcanic regions (e.g., Hough and Dreger, 1995). The results also show that the deconvolved source spectrum obtained for event E3 is atypical in two critical respects: (1) the highfrequency decay is not consistent with the expected character of a typical shear failure (i.e., classic "tectonic") event; and (2) the corner frequency, if one were to be picked, is extremely low for an event of this size. A corner frequency of 1-2 Hz for a $M 2.7$ event corresponds to a Brune stress-drop value on the order of 0.003-0.02 MPa. A stress-drop value this low is inconsistent with virtually all well-resolved stress-drop estimates for $M$ 2-3 earthquakes in tectonic environments.

Although events E1, E2, and E3 are the most clear examples of events with harmonic spectral signatures that are consistent at multiple-recording sites, a harmonic signature 
(a)

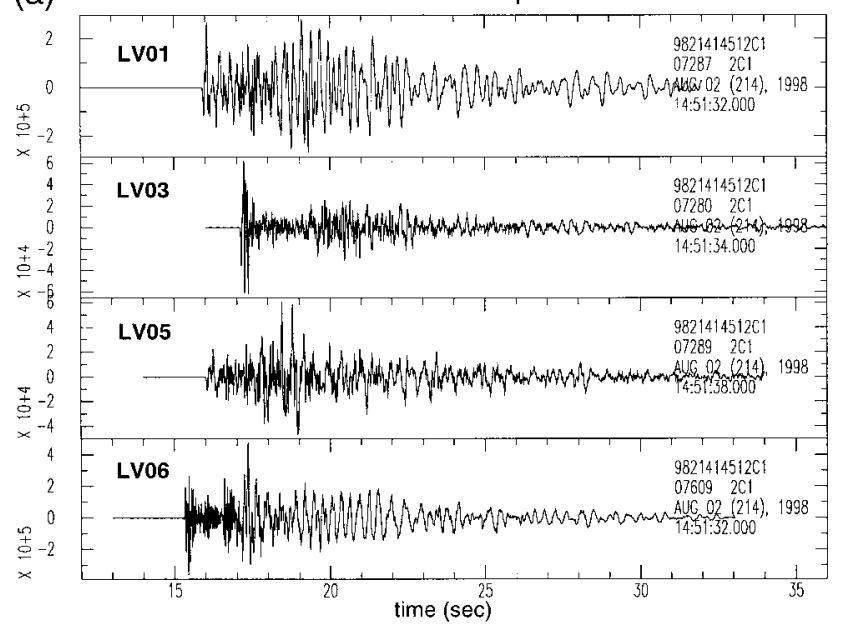

Fourier Spectra

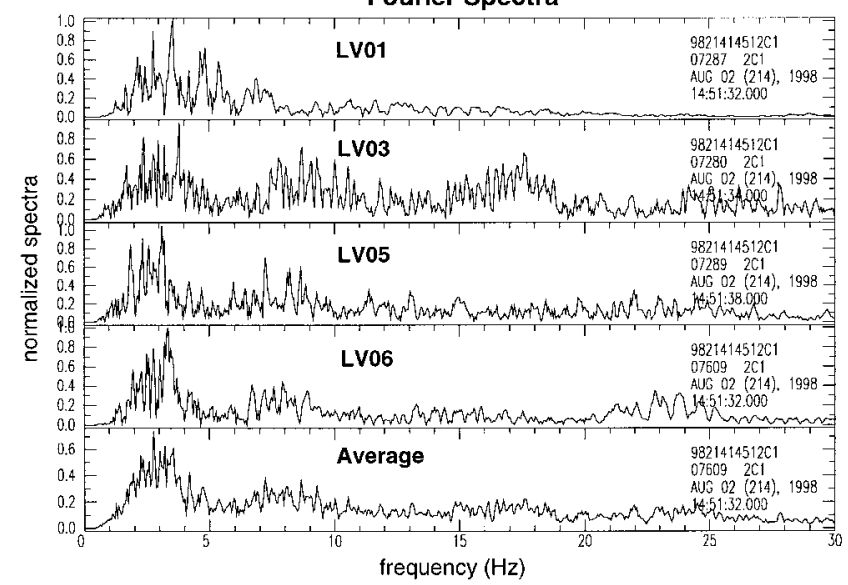

(b)

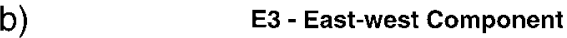
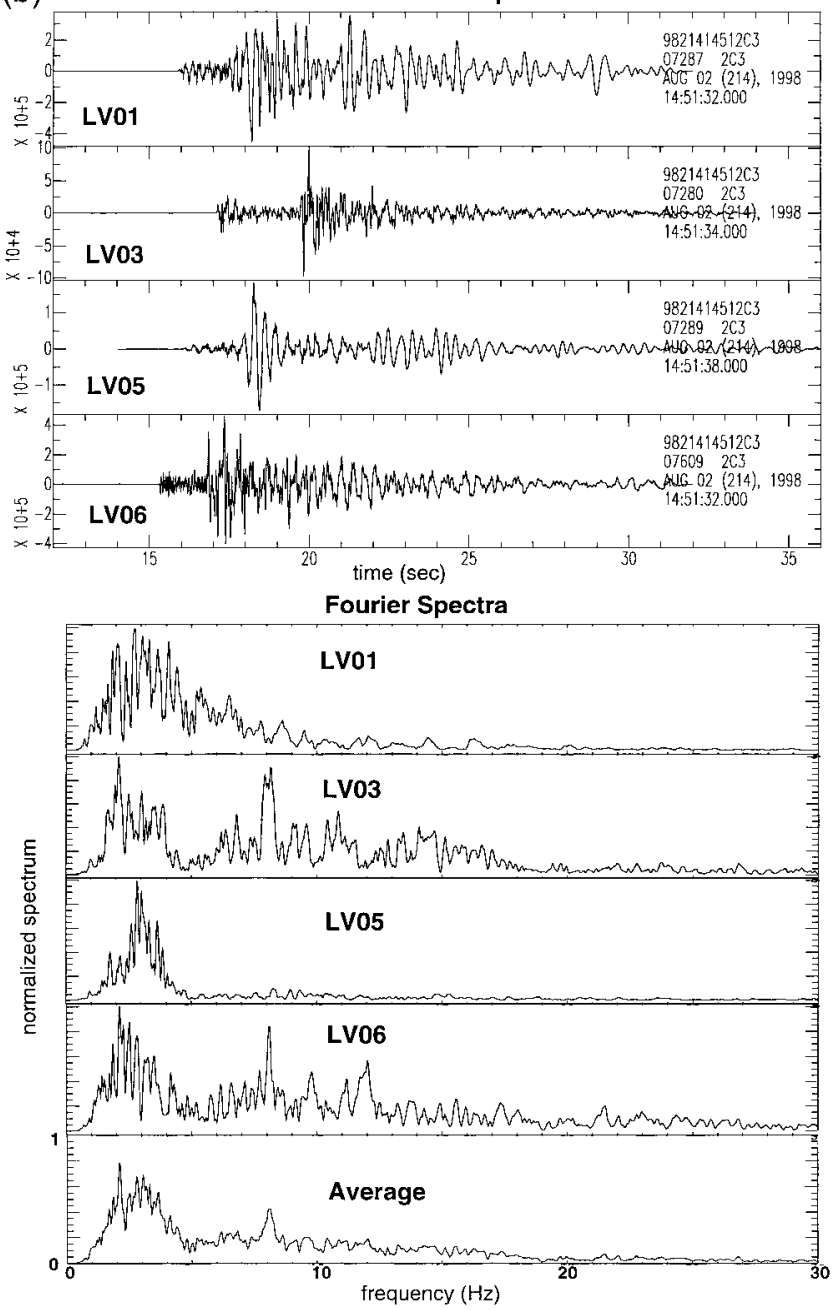

Figure 6. (a) Time series (top) and Fourier spectra (bottom) corresponding to event E3 recorded at stations LV01, LV03, LV05, and LV06. Spectra are estimated from 9sec windows bracketing the initial $P$ - and $S$-wave arrivals. An amplitude-normalized spectrum is also shown. (b) Similar to Figure 6(a), but for the east-west component at all stations.

Table 2

EGF Events

\begin{tabular}{cccccccccc}
\hline Event & Year & Day & hr:mn & Lat. & Long. & errh & errz & Depth & $\mathrm{m}$ \\
\hline 1 & 98 & 196 & $13: 34$ & 37.5655 & 118.7938 & 0.41 & 0.59 & 6.99 & 1.4 \\
2 & 98 & 197 & $04: 24$ & 37.5645 & 118.7943 & 0.56 & 1.36 & 7.15 & 1.4 \\
3 & 98 & 197 & $07: 01$ & 37.5650 & 118.7952 & 0.60 & 2.05 & 7.04 & 1.4 \\
4 & 98 & 198 & $07: 11$ & 37.5658 & 118.7943 & 0.48 & 0.72 & 6.79 & 1.4 \\
5 & 98 & 201 & $07: 10$ & 37.5687 & 118.7918 & 0.68 & 1.09 & 7.01 & 1.4 \\
\hline
\end{tabular}

Assigned event number; Year, Julian day; GMT time; latitude and longitude in decimal-degrees; horizontal and vertical errors in km; depth in $\mathrm{km}$; magnitude as determined by NCSN. is suggested in other events as well. In particular, several events occurring close in time and space to events E1-E3 are observed to have spectra that would perhaps not provide compelling evidence for a harmonic-source signature on their own but are similar to that of the preceding hybrid LP event. Figure 8(a) presents the average amplitude-normalized spectra for two events that occurred within minutes of E1. The spectrum of the 06:14 event suggests peaks that are similar to those of the $06: 11$ event (i.e., at $\approx 2-3,5-6$, and $8-9 \mathrm{~Hz}$ ) but less clearly defined. The spectrum of the 06:30 event suggests peaks that are more clearly resolved, but at somewhat higher frequencies: $\approx 3-4,8-9$, and $12-13 \mathrm{~Hz}$.

Figure 8(b) presents spectra at a single station, LV05, for event E3 and four events that occurred within minutes of this event. Although the other the spectra in Figure 8(b) are neither as strikingly harmonic nor as depleted of highfrequency $(15-25 \mathrm{~Hz})$ energy as the spectrum of event E3, 

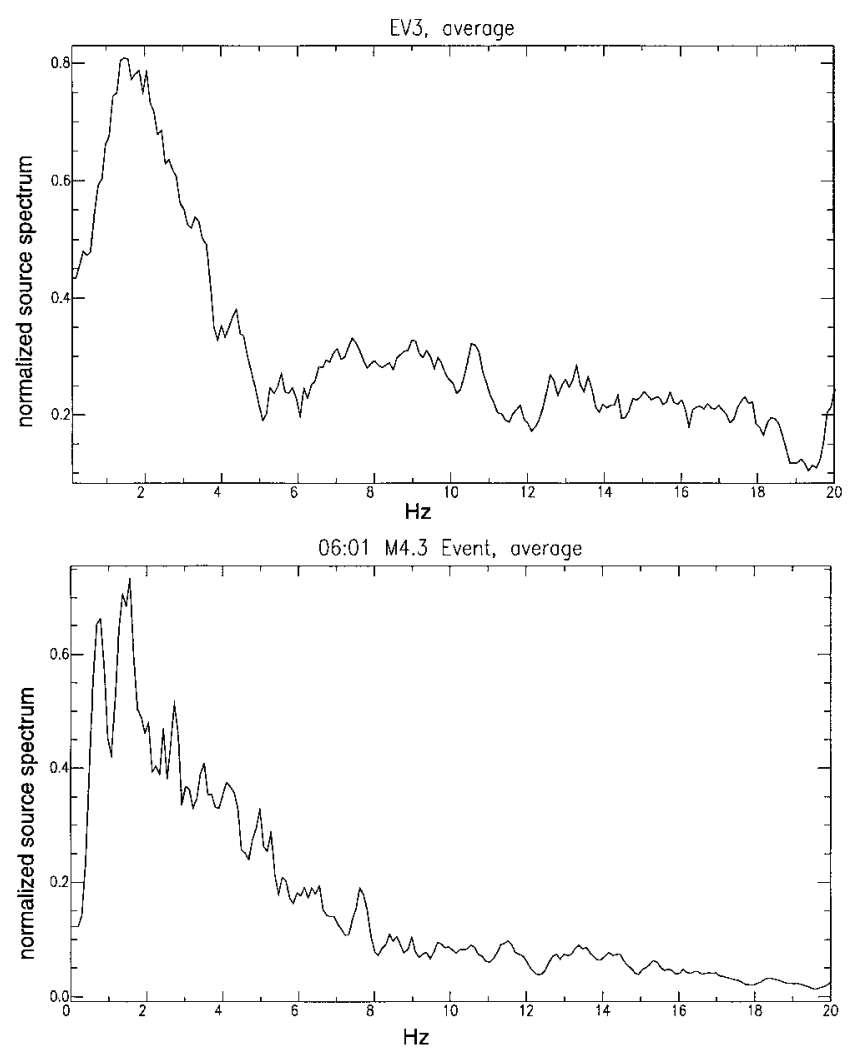

Figure 7. Top panel shows amplitude-normalized average of the deconvolved relative source spectrum for event E3. EGF deconvolutions are performed for event E3 at stations LV01, LV03, LV05, and LV06, using all available recordings of the EGF events listed in Table 1. Resulting source spectra estimated using different EGF events are averaged at each station; then the results from all stations are averaged to obtain the final result shown. Bottom panel shows amplitudenormalized average of the deconvolved relative source spectrum for the $M 4.3$ event that occurred at 06:01 on 1 August 1998.

all contain substantial spectral peaks at frequencies of 3-5 $\mathrm{Hz}$, yet the events range in magnitude from 1.3 to 1.9.

In addition to having unusual spectral characteristics, the bursts of small events that follow events E1 and E3 are unusual in another respect. As noted earlier, the $M 4.3$ "mainshocks" that precede both events E1 and E3 occur approximately 10 and 6 minutes before the inferred harmonic events. Yet in the intervals between each mainshock and the subsequent harmonic event, only a small number-2 and 3, respectively - of aftershocks occur. The bursts of activity immediately following events E1 and E3 are considerably more energetic, suggesting that these events are associated with larger strain events than the preceding $M 4.3$ mainshocks. Figure 9 and Table 3 present the NCSN-determined locations for both subsequences. In both cases, the events are spread out over a considerable lateral extent. Although network epicentral locations are associated with uncertainty, the network solutions for the events listed in Table 3 do not have especially large rms misfits. The lateral extent of the sequence following event E3 is approximately $2-3 \mathrm{~km}$; although we cannot definitively rule out the possibility that this scatter reflects observational uncertainties in locations, we note that the lateral extent is consistent with the very low inferred corner frequency for this event, that is, recasting equation (1) in terms of source radius

$$
\sigma=\frac{7}{16}\left(\frac{M_{\mathrm{o}}}{r^{3}}\right)
$$

(Eshelby, 1957), a source radius of $1-1.5 \mathrm{~km}$ implies a $\sigma$ of $0.01-0.05 \mathrm{MPa}$ for a $M 2.7$ event. This range is consistent with that inferred from the corner frequency $(0.003-0.02$ $\mathrm{MPa}$ ).

Returning to the spectral observations, we note that the lower-frequency peaks evident in Figure 8(b) could reflect a site response at this station. However, Figure 10 presents time series and spectra for a typical small event; the spectrum from station LV05 reveals a peak around $8 \mathrm{~Hz}$ that is plausibly associated with site response, but little energy at frequencies below $5 \mathrm{~Hz}$. Strong spectral peaks are suggested in others of the spectra as well, but they vary considerably from station to station as would be expected for the sitespecific response of the near-surface layers. The near-surface geology of the caldera region is complex. Station LV01 is located on the Bishop Tuff formation and typically characterized by notably scattered waveforms. Station LV03 is located on layered basalt flows near the edge of Mammoth Mountain. Several stations in the south moat region are close to active geothermal regions, where shallow abundant fluids are likely to give rise to significant site response. For consistent harmonic peaks to be evident at such a diverse collection of stations the signal must reflect the signature of the source itself.

Since both scattering and site response will tend to obscure the nature of the source, it is possible that other harmonic events have gone undetected in the data set. If an event had spectra that were as harmonic as those shown in Figure 8 but less compelling than events E1, E2, and E3, it might well elude detection. However, no examples as clear as the three early August events have been found elsewhere within the STORMS data set. Moreover, the significance of such events does not hinge on the quantity of similar events observed.

\section{Interpretation and Conclusions}

The waveform and spectral observations suggest a fluidcontrolled source process. However, interpretation of such events is inevitably plagued by a fundamental ambiguity between different source processes that can give rise to a harmonic spectral signature. That is, spectra such as those shown here can be associated with either volcanic (magmatic/fluid-controlled) events or with tectonic (brittle shear 
(a)

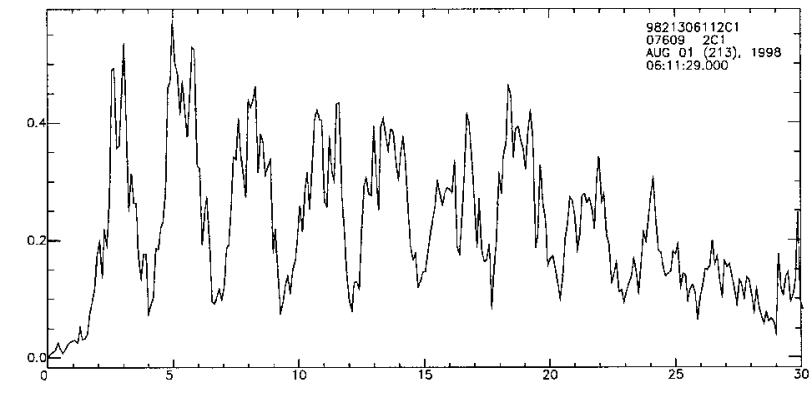

$06: 14$

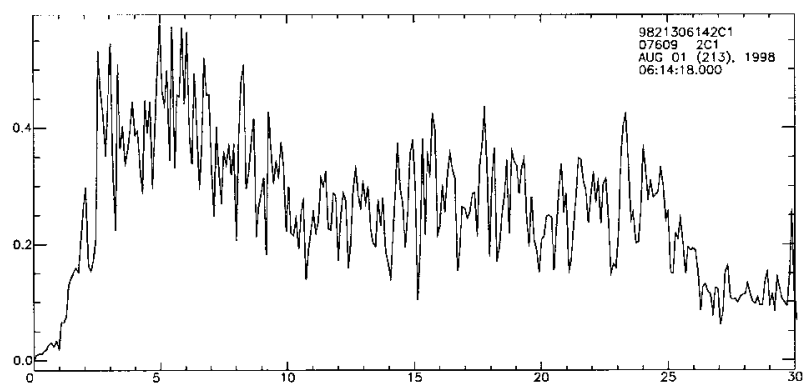

$06: 30$

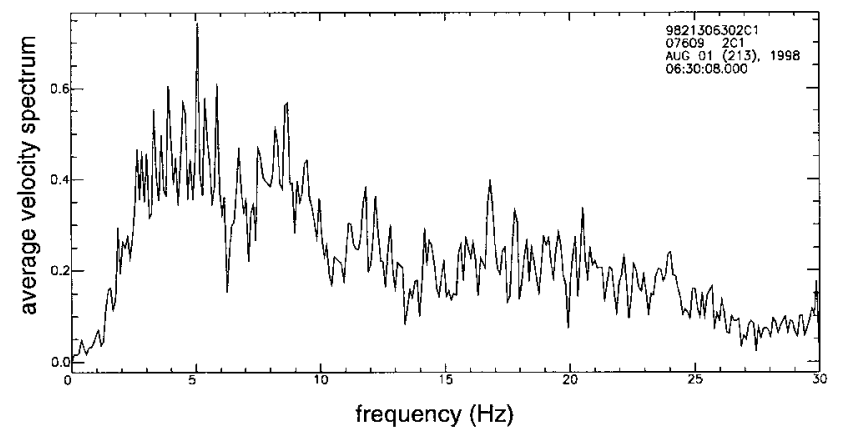

(b)

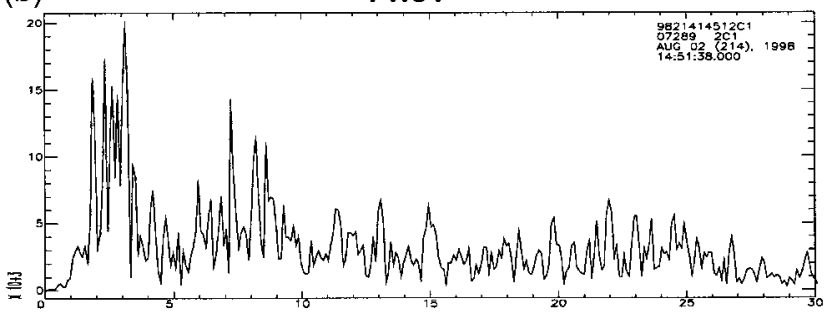

14:52

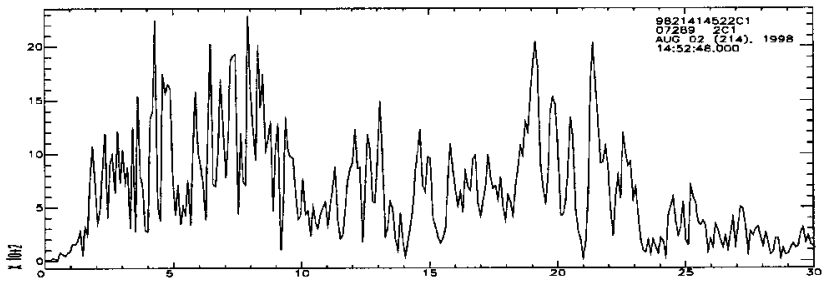

14:53

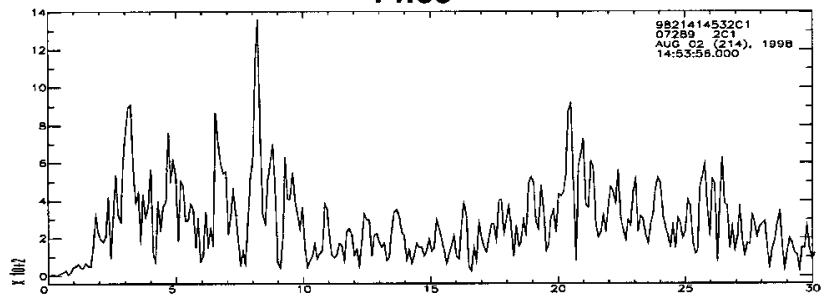

14:57
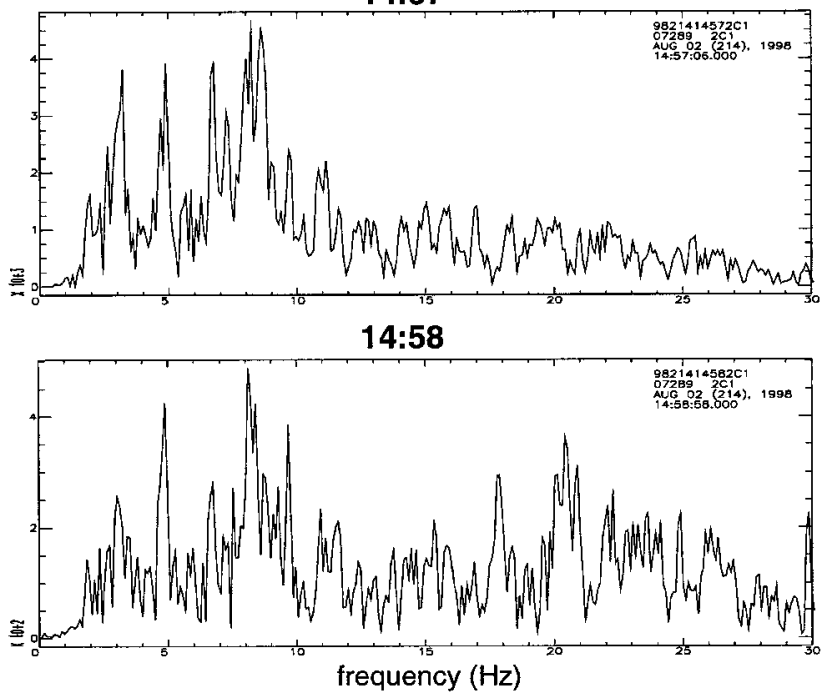

Figure 8. (a) Amplitude-normalized averages of Fourier spectra from stations LV01, LV03, LV05, and LV06 corresponding to events E1 and two small events $(M$ 1.1 and $M 1.3$ ) that occurred approximately 3 and 19 minutes after E1, respectively. (b) Fourier spectra from station LV05 for event E3 and four small events that occurred within minutes of this event. Respectively, the events occur at 14:52, 14:53, 14:57, and 14:58, and have NCSN-determined magnitudes of 1.9, 1.3, 1.6, 1.9, and 1.4.

failure) earthquakes that involve distinct subevents. A subevent occurring at a delay of $t_{\mathrm{s}}$ will give rise to a spectral peak at $1 / t_{\mathrm{s}}$. Alternatively, a harmonic signature can result from a source process characterized by repeated excitation associated with the interaction between a single or multi- phase fluid and the surrounding rock. We argue that four lines of evidence argue against the former interpretation: (1) the multiple (upwards of five) similar, nearly periodic arrivals evident in recordings of event E1. Tectonic subevents are highly unlikely to be this regular in time; (2) the simi- 


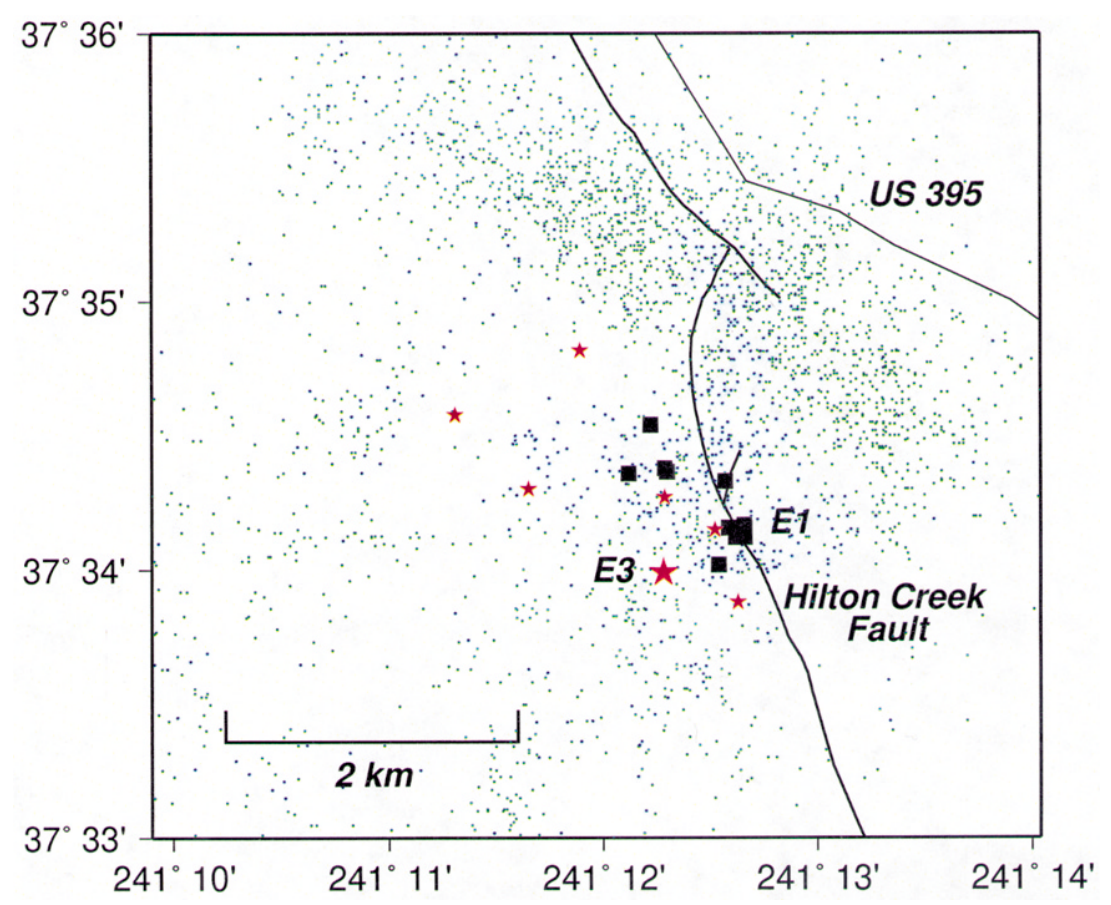

Figure 9. Small green dots indicate earthquakes in June and July 1998; blue dots indicate events in August 1998. Black squares indicate the subsequence of small events that occurred within minutes of event E1; red stars indicate sequence that occurred within minutes of event E3. Events E1 and E3 are indicated with larger square and star. See Table 3 for event lists.
Table 3

Events Following E1, E3

\begin{tabular}{cccccccccc}
\hline Seq. & Year & Day & hr:mn & Lat. & Long. & errh & errz & Depth & $\mathrm{m}$ \\
\hline E1 & 98 & 213 & $6: 11$ & 37.5690 & 118.7893 & 0.30 & 0.98 & 3.71 & 1.30 \\
E1 & 98 & 213 & $6: 12$ & 37.5722 & 118.7905 & 0.25 & 0.74 & 4.12 & 1.50 \\
E1 & 98 & 213 & $6: 14$ & 37.5670 & 118.7910 & 0.32 & 1.14 & 3.51 & 1.10 \\
E1 & 98 & 213 & $6: 15$ & 37.5695 & 118.7890 & 0.38 & 1.26 & 3.93 & 1.20 \\
E1 & 98 & 213 & $6: 17$ & 37.5727 & 118.7980 & 0.34 & 1.02 & 3.80 & 1.10 \\
E1 & 98 & 213 & $6: 18$ & 37.5728 & 118.7950 & 0.63 & 2.02 & 4.10 & 0.90 \\
E1 & 98 & 213 & $6: 27$ & 37.5730 & 118.7952 & 0.34 & 1.34 & 4.05 & 1.10 \\
E1 & 98 & 213 & $6: 28$ & 37.5693 & 118.7902 & 0.33 & 1.13 & 3.59 & 1.00 \\
E1 & 98 & 213 & $6: 30$ & 37.5757 & 118.7963 & 0.38 & 0.89 & 3.93 & 1.30 \\
E3 & 98 & 214 & $14: 51$ & 37.5665 & 118.7953 & 0.28 & 0.59 & 6.97 & 2.67 \\
E3 & 98 & 214 & $14: 52$ & 37.5717 & 118.8058 & 0.37 & 0.57 & 6.04 & 1.90 \\
E3 & 98 & 214 & $14: 53$ & 37.5763 & 118.8115 & 1.21 & 1.61 & 7.07 & 1.30 \\
E3 & 98 & 214 & $14: 54$ & 37.5692 & 118.7913 & 0.38 & 0.60 & 7.14 & 1.60 \\
E3 & 98 & 214 & $14: 57$ & 37.5803 & 118.8018 & 0.29 & 0.49 & 6.36 & 1.90 \\
E3 & 98 & 214 & $14: 57$ & 37.5712 & 118.7952 & 0.39 & 0.56 & 6.91 & 1.40 \\
E3 & 98 & 214 & $14: 59$ & 37.5647 & 118.7895 & 0.47 & 1.30 & 6.81 & 1.40 \\
\hline
\end{tabular}

Sequence (E1 or E3); Year, Julian day; GMT time; latitude and longitude in decimal-degrees; horizontal and vertical errors in $\mathrm{km}$; depth in $\mathrm{km}$; magnitude as determined by NCSN.

larity between the time series from E3 and classic hybrid LP events observed in other volcanic regions (e.g., Chouet, 1996). Event E1 does not display a conspicuous low-frequency wave train, but its jagged, emergent time domain signature is suggestive of a more prolonged and complex source process than brittle shear failure; (3) the markedly low-frequency content of E3 as revealed by EGF analysis (see Fig. 7); and (4) the fact that the timing of these events corresponds so closely with the "aftershock sequence with- out a mainshock" shown in Figure 2(b). The burst of seismicity that began on 1 August 1998 is itself suggestive of a strain event larger than the earthquake activity accounts for. That is, while one cannot prove conclusively that the burst of seismicity that began on 1 August was not simply an energetic aftershock subsequence, the coincidence of this burst and the timing of the harmonic events provides a measure of mutual corroboration for the hypothesis that both observations were associated with a strain event associated with magmatic activity.

Hybrid LP events have been observed previously in active volcanic regions including Long Valley (e.g., Fehler and Chouet, 1982; Cramer and McNutt, 1997) and have been interpreted in terms of active magmatic processes (e.g., Chouet, 1992). Such events have, moreover, not been observed outside of active volcanic regions. While it is possible that such events occur elsewhere but have gone undetected, we consider the possibility relatively unlikely in view of the many high-resolution investigations of small-to-moderate event source properties published in recent years (e.g., Abercrombie and Leary, 1993; Hough and Dreger, 1995; Nadeau and Johnson, 1998). Although a number of specific mechanisms have been proposed to account for the LP events and sustained harmonic tremor observed in volcanic regions (see Chouet et al., 1987; Julian et al., 1998), all involve the interaction of a single- or multiphase fluid with the surrounding rock.

In an active volcanic region, fluid migration could be associated with either magmatic injection or hydrothermal fluids/brine. Lachenbruch et al. (1976) showed that the production zone of the commercial geothermal field at Long Valley is restricted to the upper $1-2 \mathrm{~km}$. However, there is 

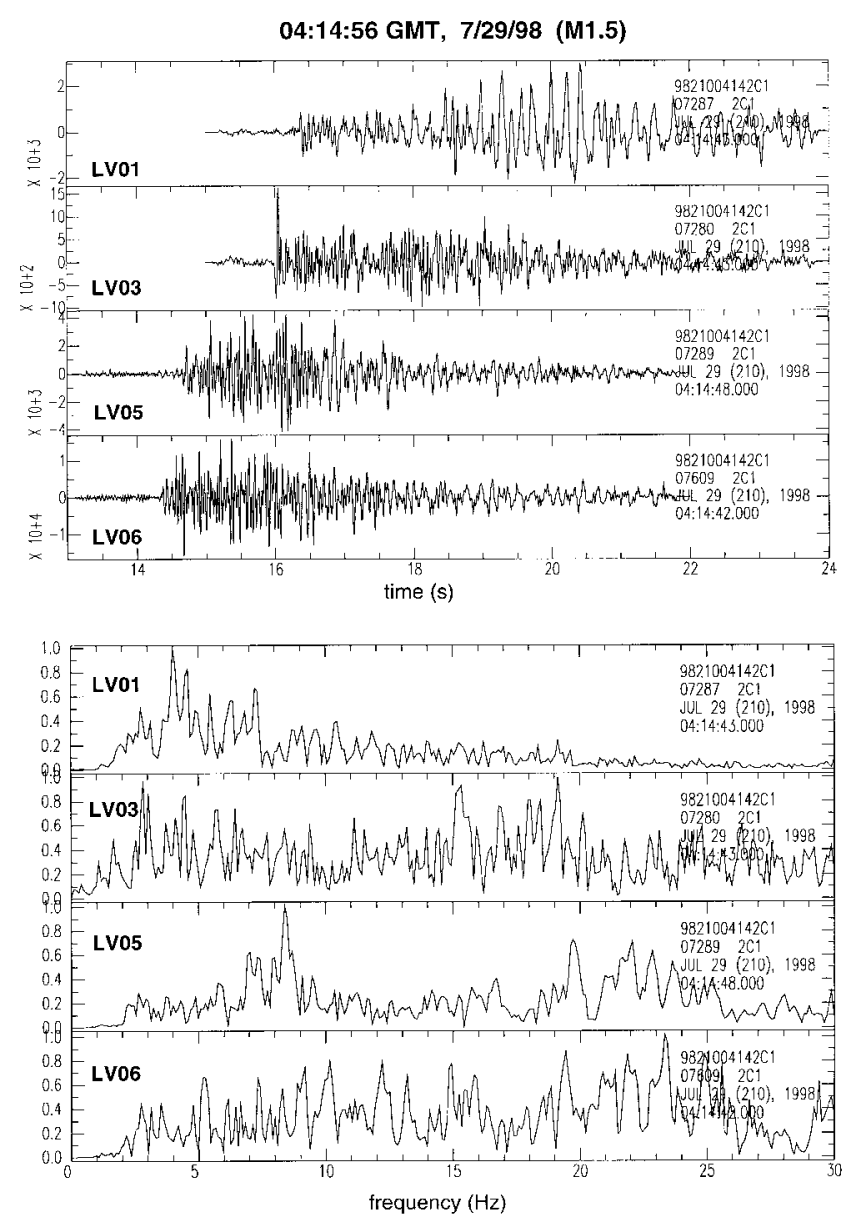

Figure 10. Vertical-component time series (top) and Fourier spectra (bottom) corresponding to a typical event recorded by the STORMS network. The event is a $M 1.5$ earthquake at 04:14:56 GMT on 29 July 1998, with a network location of $37.6350 \mathrm{~N}$, $118.8303 \mathrm{~W}$, and a depth of $4.63 \mathrm{~km}$.

evidence that the hydrothermal system pervades a much larger volume of crust (Hill, 1992). It is therefore impossible to rule out the possibility that our inferred harmonic events are associated with the migration of brines or hydrothermal fluids derived from a central magma body, or even with water of meteoric origin. We note, however, that our observations are also plausibly explained by a magmatic (or dike) injection process at 3-7 km depth. Because hybrid LP events have not (to date) been observed outside of active volcanic regions/geothermal regions, we conclude that either magma or magma-derived fluids are the most likely candidates for fluid-controlled sources. This, in turn, provides evidence for the presence of magma either within the SNB, or in close proximity to it.

Whether the fluids are magmatic are aqueous is, nonetheless, difficult to determine conclusively. Of the additional data that could be diagnostic, such as GPS or CO2, little is available for the SNB region. Assuming a dike-injection process, one can estimate viscosity, $\eta$, from

$$
\eta=\frac{\tau(\delta P)}{12 r^{2}}
$$

where $\tau$ is the duration of the injection process, $r$ is the vertical aspect ratio, and $\delta P$ is the driving pressure (Julian and Sipkin, 1985). Following Julian and Sipkin, plausible values of $r$ and $\delta P$ can be assumed to be 100-1000 $\mathrm{m}$ and 10-100 MPa, respectively. While all of the terms are hugely uncertain, perhaps the key question here is the appropriate value for $\tau$. If it is the short-source duration of the individual LP events (a few seconds or less), then equation (3) yields a value for $\eta$ that is low compared to inferred viscosity of magma. If, however, $\tau$ is instead taken to be the duration of the seismicity bursts following events E1 and E3 (on the order of 10 minutes), then one easily obtains viscosities as high as that expected for magma (e.g., upwards of $100 \mathrm{~N}$. $\mathrm{sec} / \mathrm{m}^{2}$ ).

Earlier studies do suggest the presence of magma and or magmatic events within the SNB. Events E1, E2, and E3 occur close to previously identified potential magma zones (Ryall and Ryall, 1984; Peppin et al., 1989). Wiemer et al. (1998) recently presented intriguing results showing that significant spatial variations in the seismic $b$-value are observed at Long Valley. The authors suggest that unusually high $b$ values reflect a high degree of fracturing and/or high pore pressures, both of which are plausibly associated with magma bodies. Although Wiemer et al. (1998) show that the most pronounced (and deepest) high $b$-value anomalies are found beneath the resurgent dome and Mammoth Mountain, they image a less pronounced high $b$-value region in the vicinity of the harmonic events documented in this study, at a depth range of roughly $1-5 \mathrm{~km}$.

A high-attenuation region in the same area (at a depth range of roughly 4-7 km) was also imaged in the tomographic investigation of Sanders et al. (1995). Although on the fringes of their study area, the attenuation anomaly is significant in amplitude and centered around coordinates $37.58^{\circ} \mathrm{N},-118.78^{\circ} \mathrm{W}$, within 0.01 degrees of events $\mathrm{E} 1$ and $\mathrm{E} 3$.

Based on the evolution of the 1997-1998 sequence and the observations presented briefly in this article, one can speculate on the interaction between tectonic and volcanic processes at Long Valley. The 1997-1998 episode of seismic unrest was preceded by an upswing in deformation data (Hill et al., 1998) that Langbein et al. (1998) interpret in terms of an intrusion event under the resurgent dome as well as a component of strike-slip motion within the south moat. Such an event will clearly provide a source of regional strain (Savage and Clark, 1982). A spattering of regional seismicity -10 events with $M 4.0-5.0$ at distances of roughly 50 $100 \mathrm{~km}$ of the caldera-occurred in 1997-1998 and is plausibly associated with this strain. Savage and Clark (1982) showed that inflation beneath the resurgent dome would give rise to tensile stresses in the SNB region. The nature of the extensional processes in the SNB has been investigated recently via detailed seismotectonic analyses. Hill (1998) sug- 
gested that seismic activity in the SNB region could reflect transtensional deformation accommodated by a system of conjugate fault systems. Johnson and Seeber (1999) proposed that faulting and seismicity in the SNB reflects an ongoing process of block rotation in accommodation of the strain resulting from magmatic processes. In particular, they proposed that right-lateral slip along an EW-trending south moat fault will be accommodated by clockwise block rotation within the SNB to the south.

Finally, we offer a speculative interpretation of the summer 1998 earthquake activity in the SNB region. We suggest that the June and July $M 5.1$ events (and their immediate aftershock sequences) reflected a tectonic adjustment to the previous intrusion event but that extensional processes associated with this adjustment provide an opportunistic "escape route" for either magma or magma-derived fluids to extend laterally away from a primary magma source beneath the resurgent dome. The August hybrid LP events may therefore be associated with incipient vein/dike intrusion into the SNB at depths of perhaps 4-7 km. This conclusion parallels the interpretation of Malin et al. (1998) and Foulger et al. (1998), who observed similar hybrid LP events in the south moat region in the summer of 1997 and concluded that the events reflected an incipient dike injection process beneath the resurgent dome.

The presence of magma or magmatic fluids within the SNB, which must clearly be highly fractured by the substantial ongoing tectonic processes, is not surprising. Given that the Mono/Inyo eruptions occurred well outside the caldera, it is clear that either magma sources exist beneath a fairly broad region in the Long Valley area or else magma is able to migrate laterally from a central source. Moreover, the limited duration of the early August sequence (or inferred strain event) and the small number of hybrid LP events suggest a fairly small-scale magmatic process of vein/dike injection that in no way implies an eruption hazard in the foreseeable future. Also, it remains true that recent geologic history still suggests the Mono/Inyo chain to be the most likely site of future volcanic activity. However, the observations presented in this article provide further evidence for the extension of the magmatic system to the SNB and possible insight into the long-term evolution of the complex caldera system.

\section{Acknowledgments}

The authors are indebted to IRIS/PASSCAL for their prompt response to our instrument request and exemplary technical/field support throughout the course of our experiment. We also gratefully acknowledge the fieldwork and/or organizational contributions of David Hill, Peter Malin, Bruce Julian, Yehuda BenZion, Emily Brodsky, Nano Seeber, Chris Farrar, Dan Lyster, Josh Feinberg, Robert Drake, Robert Brooks, Scott Roripaugh, Juli Baldwin, Paul Slice, and Joshua Slice. We also thank Emily Brodsky, Kerry Sieh, Ken Hudnut, Nano Seeber, Steve McNutt, Lee Steck, and David Hill for reviews that were thorough and unfailingly constructive in their criticism.

\section{References}

Abercrombie, R., and P. C. Leary (1993). Source parameters of small earthquakes recorded at $2.5 \mathrm{~km}$ depth, Cajon Pass, California: implications for earthquake scaling, Geophys. Res. Lett. 20, 1511-1514.

Bailey, R. A. (1989). Geologic map of Long Valley Caldera, Mono-Inyo craters volcanic chain and vicinity, Mono County, California, U.S. Geol. Surv. Misc. Inves. Map I-1933.

Bailey, R. A. and D. P. Hill (1990). Magmatic unrest at Long Valley Caldera, California, 1980-1990, Geoscience Canada 17, 175-179.

Battaglia, M., C. W. Roberts, and P. Segall (1998). Constraining the source of historical unrest at large Quaternary silicic calderas using deformation and gravity data, (abstract), Trans. Am. Geophys. U. 79, 963.

Brune, J. N. (1970). Tectonic stress and the seismic shear waves from earthquakes, J. Geophys. Res. 75, 4997-5009.

Chouet, B. (1992). A seismic model for the source of long-period events and harmonic tremor, in IAVCEI Proc. in Volcanology, P. Gasparini, R. Scarpa, and K. Aki (Editors), Springer-Verlag, Berlin, 133-156.

Chouet, B. (1996). Long-period volcano seismicity: its source and use in eruption forecasting, Nature 380, 309-316.

Chouet, B., R. Koyangi, and K. Aki (1987). The origin of volcanic tremor in Hawaii, Part II: theory and discussion, U.S. Geol. Surv. Profess. Pap. 1350, 1259-1280.

Cramer, C. H., and S. R. McNutt (1997). Spectral analysis of earthquakes in the 1989 Mammoth Mountain swarm near Long Valley, California, Bull. Seism. Soc. Am. 87, 1454-1462.

Eshelby, J. D. (1957). The determination of the elastic field of an ellipsoidal inclusion and related problems, Proc. Roy. Soc. London A 241, 376396.

Fehler, M., and B. Chouet (1982). Operation of a digital seismic network on Mount St. Helens volcano and observation of long-period seismic events that originate under the volcano, Geophys. Res. Lett. 9, 10171020.

Foulger, G. R., P. E. Malin, E. Shalev, B. R. Julian, and D. P. Hill (1998). Seismic monitoring and activity increase in California caldera, Trans. Am. Geophys. U. 79, 357-363.

Hill, D. P. (1984). Monitoring unrest in a large silicic caldera, the Long Valley-Inyo craters volcanic complex in east-central California, Bull. Volcanol. 47, 371-395.

Hill, D. P. (1992). Temperatures at the base of the seismogenic crust beneath Long Valley caldera, California, and the Phlegrean Fields caldera, Italy, in IAVCEI Proc. in Volcanology, P. Gasparini, R. Scarpa, and K. Aki (Editors), Springer-Verlag, Berlin, 133-156.

Hill, D. P. (1998). An overview of the 1997-1998 unrest in Long Valley Caldera, California, (abstract), Trans. Am. Geophys. U. 79, 949.

Hill, D. P., R. A. Bailey, and A. S. Ryall (1985). Active tectonic and magmatic processes beneath Long Valley caldera, eastern California, a summary, J. Geophys. Res. 90, 11111-11120.

Hill, D. P., W. L. Ellsworth, W. L. Johnston, M. J. S. Langbein, J. O. Oppenheimer (1990). The 1989 earthquake swarm beneath Mammoth Mountain, California-an initial look at the 4 May through 30 September activity, Bull. Seism. Soc. Am. 80, 325-339.

Hill, D. P., B. R. Julian, G. R. Foulger, G. K. Sharer, and E. Brodsky (1997). The 1997 Mammoth Wave Propagation Experiment: a microearthquake study at Mammoth Mountain, California (abstract), Trans. Am. Geophys. U. 102, F443.

Hough, S. E., and D. S. Dreger (1995). Source parameters of the 4/23/92 Joshua Tree, California, earthquake and its aftershocks: empirical Green's function analysis of TERRAscope and GEOS data, Bull. Seism. Soc. Am. 85, 1576-1590.

Johnson, P. A. B., and L. Seeber (1999). Faulting within the mountain block south of Long Valley Caldera (abstract), Seism. Res. Lett. 70, 272.

Julian, B. R., and S. A. Sipkin (1985). Earthquake processes in the Long Valley Caldera area, California, J. Geophys. Res. 90, 11155-11169.

Julian, B. R., A. D. Miller, and G. R. Foulger (1998). Non-double-couple earthquakes 1. theory, Rev. Geophys. 36, 525-549. 
Keilis-Borok, V. I. (1959). On the estimation of the displacement of an earthquake source and of source dimension, Ann. Geofis. 12, 205214.

Lachenbruch, A. H., M. L. Sorey, R. E. Lewis, and J. H. Sass (1976). The near-surface hydrothermal regime of Long Valley caldera, J. Geophys. Res. 81, 763-768.

Langbein, J. R., D. Dzurisin, G. Marshall, R. Stein, and J. Rundle (1995). Shallow and peripheral volcanic sources of inflation revealed by modeling 2-color geodimeter and leveling data from Long Valley Caldera, California, 1988-1992, J. Geophys. Res. 100, 12487-12495.

Langbein, J., S. Wilkinson, M. J. S. Johnston, J. Feinberg, and R. Bilham (1998). The 1997-98 inflation of Long Valley caldera and comparison with 1989-1995 episode (abstract), Trans. Am. Geophys. U. 79, 963.

Malin, P., E. Shalev, D. Scheupner, A. Stroujkova, L. Boyd, M. Alvarez, and D. Lyster (1998). The 1997 Mammoth Wave Propagation Experiment: $S$-wave splitting, fault-guided waves, seismotectonics, and exotic sources in the Casa Diable area, Trans. Am. Geophys. U. 78, F443.

Marshall, G. A., J. Langbein, R. S. Stein, M. Lisowski, and J. Svarc (1997). Inflation of Long Valley Caldera, California, Basin and Range strain, and possible Mono Craters dike opening from 1990-94 GPS surveys, Geophys. Res. Lett. 24, 1003-1006.

Miller, A. D., G. R. Foulger, and B. R. Julian (1998). Non-double-couple earthquakes 2. observations, Rev. Geophys. 36, 551-568.

Mueller, C. S. (1985). Source pulse enhancement by deconvolution of an empirical Geer's function, Geophys. Res. Lett. 12, 33-36.

Nadeau, R. M., and L. R. Johnson (1998). Seismological studies at Parkfield VI: moment release rates and estimates of source parameters for small repeating earthquakes, Bull. Seism. Soc. Am. 88, 790-814.

Peppin, W. A., W. Honjas, T. D. Delaplain, and U. R. Vetter (1989). The case for a shallow-crustal anomalous zone (magma body?) near the south end of the Hilton Creek fault, California, including new evidence from an interpretation on pre-S arrivals, Bull. Seism. Soc. Am. 79, 805-812.

Ryall, A. S., and F. D. Ryall (1983). Shallow magma bodies related to lithospheric extension in the western Great Basin, western Nevada and eastern California, Earthquake Notes 55, 11.

Sanders, C. O., S. C. Ponko, L. D. Nixon, and E. A. Schwartz (1995). Seismological evidence for magmatic and hydrothermal structure in Long Valley caldera from local attenuation and velocity tomography, J. Geophys. Res. 100, 8311-8326.

Savage, J. C., and M. M. Clark (1982). Magmatic resurgence in Long Valley California-possible cause of the 1980 Mammoth Lakes earthquake sequence, Science 217, 531-533.

Sieh, K., and M. Bursik (1986). Most recent eruption of the Mono Craters, eastern central California, J. Geophys. Res. 91, 2539-2371.

Simons, M., R. Lohman, E. Chapin, S. Hensley, P. A. Rosen, S. Shaffer, and F. H. Webb (1998). Sources of deformation in Long Valley Caldera (abstract), Trans. Am. Geophys. U. 79, 963.

Wallace, T. (1985). A reexamination of the moment tensor solutions of the 1980 Mammoth Lakes earthquakes, J. Geophys. Res. 90, 1117111176.

Wiemer, S., S. R. McNutt, and M. Wyss (1998). Temporal and three-dimensional spatial analyses of the frequency-magnitude distribution near Long Valley Caldera, California, Geophys. J. Int. 134, 409-421.

U.S. Geological Survey

Pasadena, California

Manuscript received 29 July 1999. 